\title{
Osmotic Fragility and Some Hematological Implications of Chronically Administered Carbamazepine is Attenuated by Resveratrol and Vitamin E Combination
}

\author{
Aliyu $\mathrm{M}^{* 1}$, Saleh M I A ${ }^{2}$, Alhassan $\mathrm{AW}^{2}$, Zuberu J ${ }^{3}$ and Adamu BY \\ ${ }^{1}$ School of Post Basic otorhinolaryngology Nursing, National Ear Care Centre Kaduna, Nigeria \\ ${ }^{2}$ Department of Human Physiology, Faculty of Medicine, Ahmadu Bello University, Zaria \\ ${ }^{3}$ BM Diagnostics Services, Kaura Namoda, Zamfara State
}

${ }^{4}$ Department of Human Physiology, Faculty of Basic Medical Sciences, Bauchi State University, Gadau, Nigeria

*Corresponding author: Munira Aliyu, School of Post Basic otorhinolaryngology Nursing, National Ear Care Centre Kaduna,

Nigeria, Email: unirajamil@yahoo.com

\section{ARTICLE INFO}

Received: 幽 March 12, 2019

Published: March 20, 2019

Citation: Aliyu M, Saleh M I A, Alhassan AW2, Zuberu J, Adamu BY. Osmotic Fragility and Some Hematological Implications of Chronically Administered Carbamazepine is Attenuated by Resveratrol and Vitamin E Combination. Biomed J Sci \& Tech Res 16(2)2019. BJSTR. MS.ID.002813.

\author{
ABSTRACT
}

Carbamazepine (CBZ) as a drug used in the treatment of epilepsy and neuropathic pain has been shown to facilitate the effects of free radicals. Resveratrol (RESV), known as 3,5,4'-trihydroxystilbene, is found in grapes and other plant products. It effectively scavenges free radicals and other oxidants. Vitamin E (Vit E) is a lipid soluble antioxidant present in all cellular membranes. The present study assessed the combined effect of vitamin $\mathrm{E}$ and resveratrol on hematological markers of carbamazepine- induced oxidative stress. Adult male Wistar rats $(n=25)$ were randomly allotted to five groups: Group I (control) received distilled water, Group II received CBZ (50 mg/kg), Group III received CBZ(500mg/kg) and Vitamin E $(200 \mathrm{mg} / \mathrm{kg}) ;$ Group IV received of CBZ(50 $\mathrm{mg} / \mathrm{kg}$ ), and resveratrol (20 mg/kg); Group V received CBZ (50 mg/kg) and the coadministration of vitamin E $(200 \mathrm{mg} / \mathrm{kg})$ and resveratrol $(20 \mathrm{mg} / \mathrm{kg})$. Administration was done orally daily for 45 day after which animals were sacrificed and blood samples were used for biochemical analyses. Hematological parameters such as Red Blood Cell Count (RBC), White Blood Cell Count (WBC), Platelets Count (PC) and Osmotic Fragility (OF) were determined. Combination of RESV and Vit E significantly increased RBC, WBC PCV and decreased OF compared to the CBZ, RESV and Vit E treated groups respectively. In conclusion, co administration of RESV and Vit E resulted in better protective effect on CBZ induced hematological changes in rats than their respective doses of RESV and Vit E.

\section{Introduction}

Carbamazepine (CBZ) is the most frequently prescribed drug for the treatment of several forms of epilepsy; it is administered alone or in combination with other medications to treat certain types of seizures in patients with epilepsy. Its main function is reduction of sustained repetitive firing in neurones by blocking voltage-gated sodium channels. CBZ exerts its therapeutic effects through the inhibition of brain neuronal activities. It is used for the treatment of seizure disorders and trigeminal and other neuralgias [1]. This leaves the affected cells less excitable until the drug dissociates. Carbamazepine is also a GABA receptor agonist, as it has also been shown to potentiate GABA receptors made up of $\alpha 1, \beta 2$, and $\gamma 2$ subunits. This mechanism may contribute to its efficacy in neuropathic pain and manic-depressive illness. Laboratory research has further demonstrated that it is a serotonin releasing agent and possibly even a serotonin reuptake inhibitor [2] Previously, anti-epileptic drugs have been reported to influence decrease in haemoglobin concentration, Red Blood Cell (RBC), White Blood Cell (WBC) counts after long term antiepileptic therapy [3], while other studies have shown that carbamazepine in particular is associated with hematological changes such as 
leucopenia, decreased red blood cell count, decreased hemaoglobin aplastic anemia, agranulocytosis, pancytopenia, thrombocytopenia and megaloblastic anemia [4]. It has also been reported that people treated with carbamazepine showed evidence of haematological alterations [5]. Numerous studies have examined and found that carbamazepine induces oxidative stress [6,7].

Reactive metabolite of CBZ known as arene oxide has been implicated as a mechanism for cellular damages caused by this drug [8]. Vitamin E is a lipid soluble antioxidant present in all cellular membranes protecting against lipid peroxidation. It functions as a chain-breaking antioxidant by preventing chain initiation and propagation of free radical reaction and lipid peroxidation in cellular membrane. In addition to its antioxidant function, vitamin E influences the cellular response to oxidative stress through modulation of signal-transduction pathway [9]. Vitamin E was observed to significantly reduce the levels of serum glutamate oxaloacetate transaminase, serum glutamate pyruvate transaminase and bilirubin, the markers of hepatotoxicity elevated by CBZ and increases the levels of albumin and total protein depleted by CBZ [10]. Resveratrol, also known as 3,5,4'-trihydroxystilbene, is a polyphenolic phytoalexin found in grape skin [11]. It is best known for being found at high concentrations in red wine, but is also present in small amount in other plant products [11]. It has been found to possess anti-inflammatory, anti-cancer, and antioxidant properties, as well as its ability to increase lifespan in mammals [12]. Resveratrol effectively scavenges (neutralizes) free radicals and other oxidants [13] and inhibits Low Density Lipoprotein (LDL) oxidation $[14,15]$. In this work, we investigated the combined effect of resveratrol and vitamin E on CBZ induced hematological changes of Wistar rats.

\section{Materials and Methods}

This research work was carried out at the department of human physiology, Ahmadu Bello University Zaria.

\section{Chemicals and Reagents}

Vitamin E (Greenbrier International, INC. USA), Resveratrol (Mega Resveratrol Candlewood Stars Limited), Carboxymethylcellulose, Carbamazepine (Micro Labs Limited. India), Corn oil, Chloroform, Cotton wool, Digital weighing balance, and, Test tubes. All chemicals used for this study were of analytical grade.

\section{Experimental Animals}

Twenty five adult male Wistar rats were used for the study. The animals were purchased from the Animal House of the Department of Human Physiology, Faculty of Medicine, Ahmadu Bello University, Zaria. The animals were kept and allowed to acclimatize in standard laboratory cages at the Animal House of the Department of Human Physiology and access to standard animal feed and water ad libitum. The animals were divided into five groups $(n=5)$. All administrations were done orally by gavage for forty five days $[4,10]$.
Experimental protocols were in accordance with the guidelines for animal research, as stated in the NIH guidelines for the care and use of laboratory animals (National Academy of Sciences and National Institute of Health Publications, 2011).

\section{Grouping of Animals}

Group I: Rats were treated with distilled water $1 \mathrm{ml} / \mathrm{kg}$ orally for forty five days.

Group II: Rats were treated with carbamazepine $50 \mathrm{mg} / \mathrm{kg}$ orally for forty five days [4].

Group III: Rats were treated with carbamazepine $50 \mathrm{mg} / \mathrm{kg}$ and vitamin E 200mg/kg [10].

Group IV: Rats were treated with carbamazepine $50 \mathrm{mg} / \mathrm{kg}$ and resveratrol $20 \mathrm{mg} / \mathrm{kg}$ orally for forty five days [17].

Group V: Rats were treated with carbamazepine $50 \mathrm{mg} / \mathrm{kg}$, and co-administration of vitamin E $(200 \mathrm{mg} / \mathrm{kg})$ and resveratrol $(20 \mathrm{mg} /$ $\mathrm{kg}$ ) orally for forty five days.

\section{Blood Sample Collection and Assessments of Hematological Parameters}

The animals were sacrificed 24 hours after last administration. They were anaesthetized by chloroform inhalation in a closed chamber and dissected, and blood samples were collected via cardiac puncture in the laboratory of the Department of Human Physiology. Blood sample $(2 \mathrm{ml})$ was collected into EDTA bottles containing $8 \mathrm{mg}$ of disodium salt of ethylene diamine tetra-acetic acid. This was used for total blood count that include Red Blood Cell (RBC) count, White Blood Cell (WBC) count, Platelet count, Packed Cell Volume (PCV) which were determined according to the method described by [18].

\section{Erythrocytes Osmotic Fragility}

Determination of erythrocyte osmotic fragility was based on method described by Faulkner and King [19]. and modified by Oyewale [20]. It is an indirect method of determination of oxidative stress status. Briefly, $1 \mathrm{ml}$ of freshly obtained blood collected into EDTA bottles containing $8 \mathrm{mg}$ of disodium salt of ethylene diamine tetra-acetic acid from each rat was pipette into a set of test tubes containing $0.0,0.1,0.3,0.5,0.7,0.9 \mathrm{~g} / \mathrm{dl}$ of sodium chloride stock solution ( $\mathrm{pH}$ 7.4). This was followed by careful mixing and incubation for $30 \mathrm{~min}$ at room temperature $\left(26-28^{\circ} \mathrm{C}\right)$. Thereafter, the test tubes were centrifuged at $800 \times \mathrm{g}$ for $10 \mathrm{~min}$ using a centrifuge IEC HNSH (Damon/IEC Division, UK). The supernatant was transferred into a glass cuvette. The concentration of haemoglobin in the supernatant was measured colorimetrically by reading the absorbance at a wavelength of $540 \mathrm{~nm}$ using a spectrophotometer (Jenwey, 6405, Japan). The percentage haemolysis was calculated using the following formula:

$$
\text { Percentage haemolysis }=\frac{\text { Optical density of test solution }}{\text { Optical density of standard water }} \times 100
$$




\section{Statistical Analysis}

All data generated were expressed as mean \pm standard of error mean (Mean \pm S.E.M.). The data obtained were analyzed using OneWay Analysis of Variance (ANOVA), followed by Tukey's post-hoc test to compare the level of significance between groups using SPSS version 20. Values of $\mathrm{P}<0.05$ were considered significant.

\section{Results}

\section{Effect of Vitamin E and Resveratrol on Red Blood Cell Count}

Figure 1 shows the result of the effect of vitamin $\mathrm{E}$ and Resveratrol on RBC counts of male Wistar rats chronically induced with carbamazepine. Treatment with $\mathrm{CBZ}$ significantly $\mathrm{P}<0.05$ decreased RBC counts to $6.85+0.28 \times 1012 / \mathrm{L}$ in comparison to that of the normal control $(8.00+0.19 \times 1012 / \mathrm{L})$. Following treatment with vitamin $\mathrm{E}$, the result showed non-significant decrease in RBC count $(6.84+0.26 \times 1012 / \mathrm{L})$ when compared to CBZ treated group, however, treatment with Resveratrol significantly $\mathrm{P}<0.05$ increased
RBC count $(8.14+0.21 . \times 1012 / \mathrm{L})$ in comparison to CBZ treated group. Co-administration of vitamin $\mathrm{E}$ and Resveratrol also showed significant $(\mathrm{P}<0.05)$ increase in $\mathrm{RBC}$ count $(8.53+0.15 \times 1012 / \mathrm{L})$ in comparison to that of CBZ treated group.

\section{Effect of Vitamin E and Resveratrol on Packed Cell Volume}

Figure 2 shows the results of the effect of vitamin $\mathrm{E}$ and resveratrol on Packed Cell Volume (PCV) in CBZ treated rats. Administration of CBZ revealed highly significant $(\mathrm{P}<0.01)$ decrease in PCV $(39.08+1.66 \%)$ when compared to the normal control $(50.04+1.14 \%)$. Treatment with vitamin E showed increased PCV $(42.40+0.76 \%)$ but was not statistically significant when compared to CBZ treated group, however, treatment with resveratrol revealed highly significant $(\mathrm{P}<0.01)$ increase in $\mathrm{PCV}$ level to $48.88+1.43 \%$ in comparison to CBZ treated group. Combination of resveratrol and vitamin $\mathrm{E}$ also resulted in significant increase compared to $\mathrm{CBZ}$ treated group.

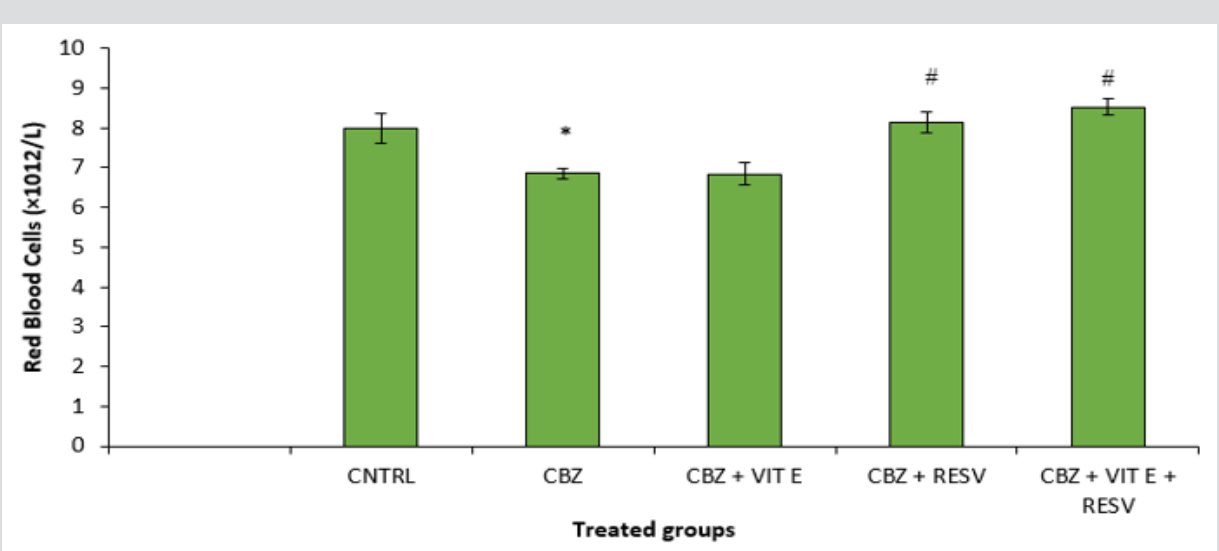

Figure 1: Effect of Vitamin E and Resveratrol on Red Blood Cell Count. CNTRL= Control; CBZ= Carbamazepine; VIT E= Vitamin E; RESV= Resveratrol. Superscripts indicate statistical significance $(\mathrm{P}<0.05)$; * and \# when compared to CNTRL and CBZ treated group respectively.

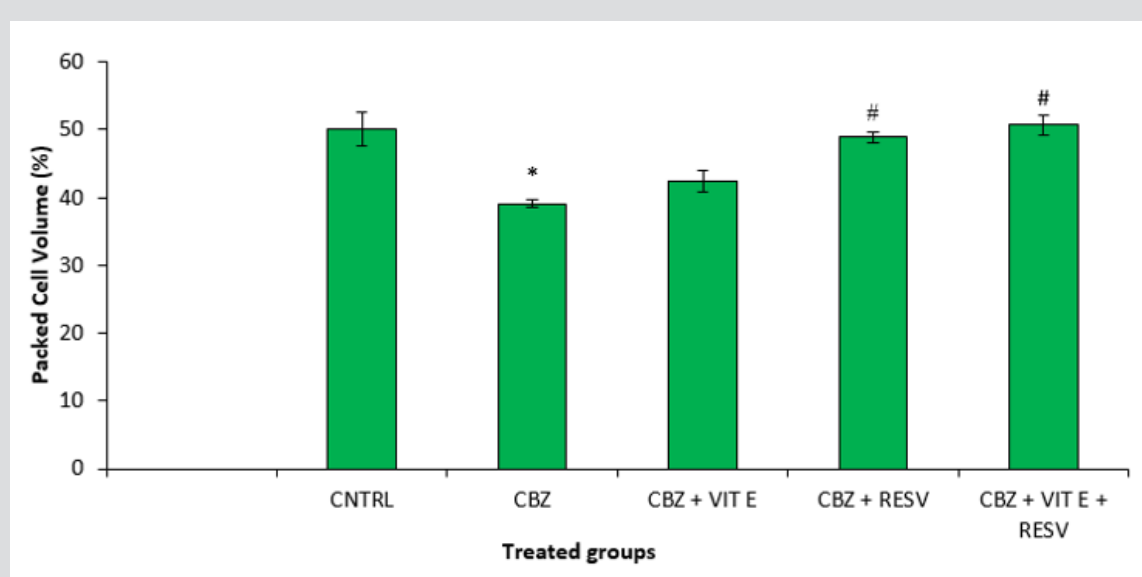

Figure 2: Effect of Vitamin E and Resveratrol on Packed Cell Volume. CNTRL= Control; CBZ= Carbamazepine; VIT E= Vitamin E; RESV= Resveratrol. Superscripts indicate statistical significance $(\mathrm{P}<0.01)$; * and \# when compared to CNTRL and CBZ treated group respectively. 


\section{Effect of Vitamin E and Resveratrol on Platelets Count}

Treatment with carbamazepine significantly $(\mathrm{P}<0.01)$ decreased platelets count $(256.00+12.20 \times 10 \times 9 / \mathrm{L})$ in comparison to that of the normal control $(314.00+7.07 \times 109 / \mathrm{L})$ as shown in Figure 3. Treatment with vitamin $\mathrm{E}$ and resveratrol revealed significant $(\mathrm{P}<0.01)$ increase in platelet count to $323.20 \pm$ $23.83 \times 109 / \mathrm{L}$ and $338.20 \pm 3.98 \times 109 / \mathrm{L}$ respectively compared to CBZ treated group. Co-administration of vitamin E and resveratrol resulted in highly significant $(\mathrm{P}<0.01)$ increase in platelet count $(361.80+80.46 \times 109 / \mathrm{L})$ compared to the CBZ treated group.

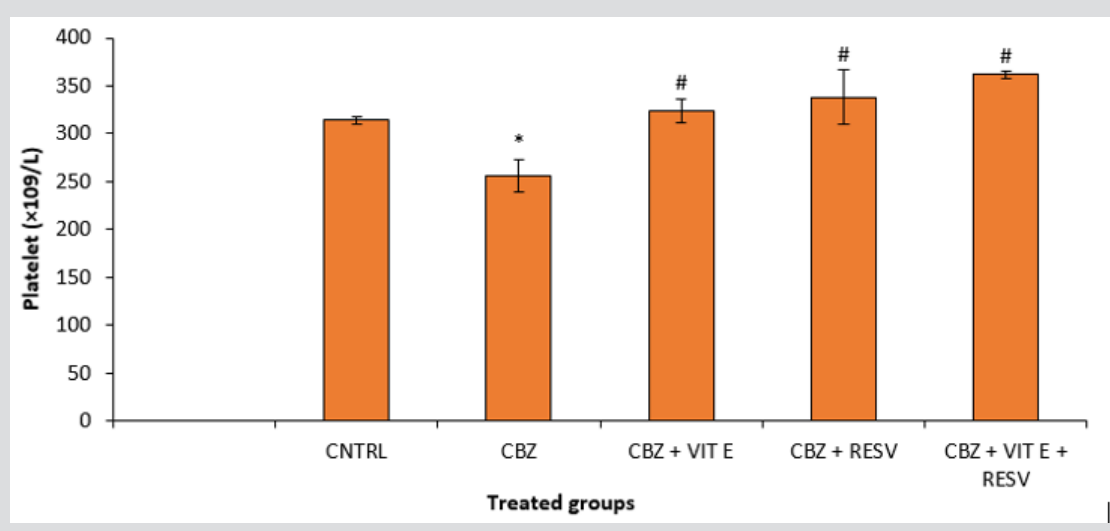

Figure 3: Effect of Vitamin E and Resveratrol on Platelet count. CNTRL= Control; CBZ= Carbamazepine; VIT E= Vitamin E; RESV $=$ Resveratrol. Superscripts indicate statistical significance $(\mathrm{P}<0.01) ;{ }^{*}$ and \# when compared to CNTRL and CBZ treated group respectively.

Effect of Vitamin E and Resveratrol on White Blood Cells Count

There was significant $(\mathrm{P}<0.01)$ decrease in WBC of Wistar rats following treatment with carbamazepine $(4.20+0.21 \times 109 / \mathrm{L})$ as shown in Figure 4 compared to the normal control group
$(6.08+0.31 \times 109 / \mathrm{L})$. Treatment with vitamin $\mathrm{E}$ and resveratrol resulted in significant increase in WBC counts $(4.80 \pm 0.41 \times 109 / \mathrm{L}$ and $5.32 \pm 0.20 \times 109 / \mathrm{L}$ ) respectively compared to CBZ-treated group. Co-administration of vitamin $\mathrm{E}$ and resveratrol showed a significant increase in WBCs count $(5.90 \pm 0.18 \times 109 / \mathrm{L})$ in comparison to the CBZ treated group.

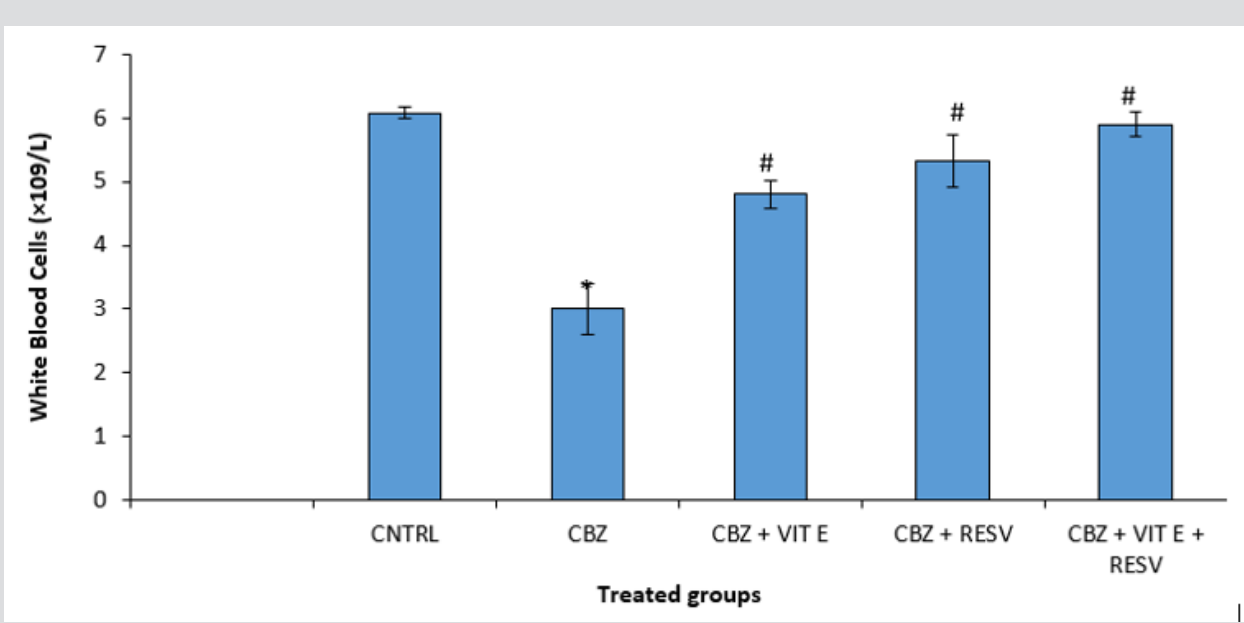

Figure 4: Effect of Vitamin E and Resveratrol on White Blood Cell count. CNTRL= Control; CBZ= Carbamazepine; VIT E= Vitamin E; RESV= Resveratrol. Superscripts indicate statistical significance $(\mathrm{P}<0.01)$; * and \# when compared to CNTRL and CBZ treated group respectively.

\section{Effect of Vitamin E and Resveratrol on Osmotic Fragility}

There was a significant increase $(\mathrm{P}<0.01)$ in lysis at $0.4 \%$ and $0.5 \%$ of Nacl concentrations of RBC of the CBZ group compared to the control group as shown in Figure 5. Treatment with resveratrol and in combination with Vit E resulted in significant decrease in lysis of RBC compared to CBZ-treated group at $0.4 \%$ and $0.6 \%$. respectively. 


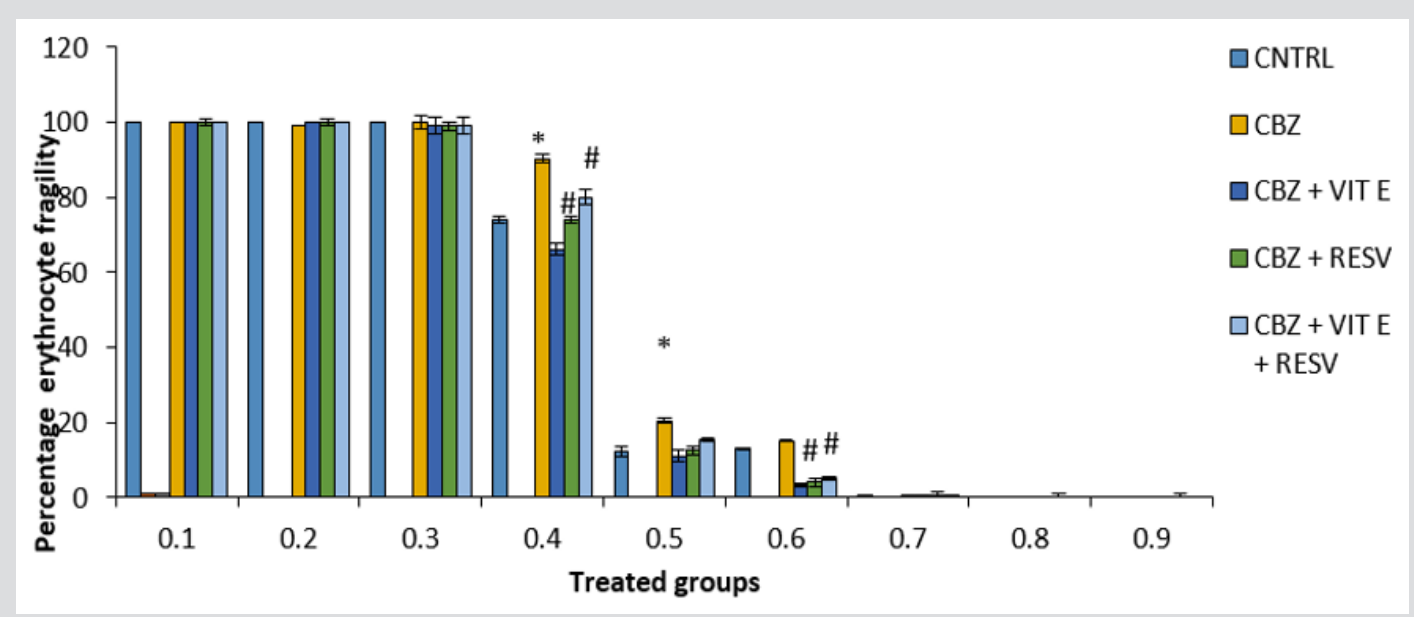

Figure 5: Effect of Vitamin $\mathrm{E}$ and Resveratrol on osmotic fragility. CNTRL= Control; $\mathrm{CMC}=\mathrm{Carboxymethylcellulose;} \mathrm{CBZ=}$ Carbamazepine; VIT E= Vitamin E; RESV= Resveratrol. Superscripts indicate statistical significance $(\mathrm{P}<0.01)$; ${ }^{*}$ and \# when compared to CNTRL and CBZ treated group respectively.

\section{Discussion}

Numerous studies have examined and found that carbamazepine induces oxidative stress, possibly via the formation of free radicals and Reactive Oxygen Species (ROS) thereby decreasing the levels of superoxide dismutase, catalase, and glutathione peroxidase, whereas it increased lipid peroxidation [4]. Oxidative stress significantly reduce total red blood cells, hemoglobin, total white blood cells including neutrophils, platelets and packed cell volume [4]. Continuous exposure to ROS renders erythrocyte sensitive to redox imbalance which in in turn increase OF due to ROS induced changes in the molecular properties of the erythrocyte [21].

In the present study, treatment of Wistar rats with CBZ significantly decreased RBC counts, PCV, PLT and WBC count compared to the normal control group. We have previously shown that CBZ can induce oxidative damage by increasing lipid peroxidation after 45 days administration [22]. The decrease in hematological parameters may be attributed to the fact that carbamazepine undergoes oxidative metabolism which result in the formation of a toxic arene oxide as an intermediate product. The oxide covalently binds with cell macromolecules causing bone marrow toxicity and aplastic anaemia [23]. Carbamazepine induced lipid peroxidation of the lipid bi-layer of cells results in subsequent compromise of cellular membrane integrity. These findings also corroborate the works of [4] who reported that carbamazepine produced a marked decrease in hemoglobin, total erythrocyte count, total leucocyte count, differential leucocyte count, platelet count and packed cell volume.

Following treatment with vitamin $\mathrm{E}$, the result showed a decrease in RBC count, but an increase in PCV and WBC count though not statistically significant when compared to CBZ treated group. However, there was significant increase in PLT compared to CBZ treated group. The non-significant decrease in RBC count may be associated with low dose of Vitamin E. The increase in PCV, PLT and WBC may be due ability of Vitamin E to scavenge lipid peroxyl radicals leading to decrease in lipid peroxidation. Treatment with resveratrol significantly increased RBC, PCV, PLT and non-significant increase in WBC counts, in comparison to CBZ treated group. This could be due to ability of Resveratrol to activate PARP 1 and this stimulate network of genes that protect cells from oxidative-induced damage [24]. This result is in agreement with Nurgül et al., [25] who investigated the protective effects of resveratrol on hematological and biochemical changes in rats induced by sodium fluoride and they found out that hematological changes were ameliorated in the group that received fluoride and resveratrol. However it is contrary to the findings of Juan et al. [16] which showed non alteration of hematological parameters following a high-dose of resveratrol administration. Furthermore, co-adminstration of Vitamin $\mathrm{E}$ and Resveratrol significantly increased RBC, PCV, WBC count and decreased OF in comparison to that of CBZ, RESV and VIT E treated groups respectively. The antioxidant activities of both Vitamin $\mathrm{E}$ and Resveratrol may have synergistically contributed in the obliteration of lipid peroxidation to reduce oxidative stress as well as the destruction of the blood cells. This result is in agreement with Alhassan et al. [26] who reported that co- administration of antioxidants showed an improvement in packed cell volume, hemoglobin concentration and red blood cell in rats subjected to heat stress. The result may imply that combination of resveratrol and vitamin E may have better synergistic effect during administration.

Red blood cells are distinctive, highly specialized and the most abundant cells in humans and contain high levels of both enzymatic and non-enzymatic cytoplasmic antioxidants [27]. They are the first cells in the body to be exposed to stressful stimuli and hence, prone to oxidative stress [27]. Because of its role as 02 and $\mathrm{CO}_{2}$ transporter, the erythrocytes are under constant exposure 
to Reactive Oxygen Species (ROS) and oxidative stress [28] The results of the present study showed a significantly increased erythrocyte osmotic fragility were recorded at 0.4 , and $0.5 \%$ of Nacl concentrations in CBZ treated groups compared to normal and resveratrol treated as well as the vitamin E treated group. This result could be due to the pro-action of CBZ on ROS level thereby resulting in lipid peroxidation of the membrane lipid bi-layers which are rich in polyunsaturated fatty acids side chains. The decrease observed in the resveratrol treated and vitamin E could have been from the antioxidant activity of the substances which enables them to mop up the prevalent reactive oxygen species, resulting in less damage to the cell membrane of the erythrocytes.

\section{Conclusion}

Co administration of resveratrol and Vitamin E exhibited a better protective effect on CBZ induced hematological changes of Wistar rats in a chronic study, more than when resveratrol and vitamin $\mathrm{E}$ are administered singly.

\section{Acknowledgement}

I thank Almighty Allah who is the author of life, wisdom and understanding for His grace, strength and success of this research work. I am grateful to all of those with whom I have had the pleasure to work during this research.

\section{References}

1. Brodie MJ, Covanis A, Gil Nagel A, Lerche H, Perucca E (2011) Antiepileptic drug therapy: Does mechanism of action matter? Epilepsy Behav 21: 331-341.

2. Kawata Y, Okada M, Murakami T, Kamata A, Zhu G, et al. (2001) Pharmacological discrimination between effects of carbamazepine on hippocampal basal evoked serotonin release. Br J Pharmacol 133(4): 557-567.

3. Jawad S, Mercer A, Jamil N, Richens A (1988) Haematological values of epileptic patients entering drug trials. Int J Clin Pharmacol Res 8(5): 363-366.

4. Thakur S, Maheswari E, Saraswathy GR (2012) Amelioration of carbamazepine induced oxidative stress and hematotoxicity by vitamin C. Spatula DD -Journal on Complementary Medicine and Drug 2(3): 173180.

5. Homez AC, Jime'nez M, Luna JR, Salazar JG, Pen JA (2004) Hematologic disorders in patients treated with carbamazepine attending the institute autonomo hospital, university of los andes, merida, Venezuela. Magazine School of Pharmacy 46: 22-26.

6. Malarvizhi A, Kavitha C, Saravanan M, Ramesh M (2012) Carbamazepine (CBZ) induced enzymatic stress in gill,liver and muscle of a common carp, Cyprinus carpio. Journal of King Saud University Science 24: 179186.

7. Eghbal MA, Taziki S, Sattari MR (2013) Protective role of melatonin and taurine against carbamazepine-induced toxicity in freshly isolated rat hepatocytes. Int J Morphol 31: 1081-1089.

8. Bavdekar SB, Muranjan MN, Gogtay NJ, Kantharia V, Kshirsagar NA (2004) Anticonvulsant hypersensitivity syndrome: Lymphocyte toxicity assay for the confirmation of diagnosisand risk assessment. Ann Pharmacother 38(10): 1648-1650.

9. Azzi A, Boscobonik D, Hensey C (1992) The protein kinase C family. European Journal of Biochemistry 208: 547-557.
10. Maheswari E, Saraswathy RG, Santhranii T (2015) Influence of vitamin E on hepatotoxicity and oxidative stress. International Journal of Research in Pharmacy and Biosciences 2(3): 30-38.

11. Bielsalski HK (2007) Polyphenols and inflammation: Basic interactions. Curr Opin Clin Nutr Metab Care 10: 724-728.

12. Baur J, Pearson KJ, Price NL (2006) Resveratrol improves health and survival of mice on a high calorie diet. Nature 444: 337-342.

13. Stojanovic S, Sprinz H, Brede O (2001) Efficacy and mechanism of the antioxidant action of trans-resveratrol and its analogues in the radical liposome oxidation. Arch Biochem Biophys 391: 79-89.

14. Frankel EN, Waterhouse AL, Kinsalla JE (1993) Inhibitory of human LDL oxidation by resveratrol. Lancet 341(8852): 1103-1104.

15. Brito PM, Derillard R, Negre salvayre A, Almeida LM, Dinis T, et al. (2009) Resveratrol inhibits the MTOR mito genic signaling evoked by oxidized LDL in smooth muscle cells. Artheroscherosis 205(1): 126-134.

16. Juan ME, Vinardell MP, Planas JM (2002) The daily oral administration of high doses of trans-resveratrol to rats for 28 days is not harmful. J Nutr 132: $257-260$

17. Rai AR, Sampath ML, Prabhu V, Vasudha V, Sudhanshu S, et al. (2013) Resveratrol reverses the restraint stress-induced cognitive dysfunction involving brain antioxidant system in rats. International Journal of Pharmacy and Pharmaceutical Science 6(1): 768-772.

18. Dacie JV, Lewis SM (1991) Practical Haematology ( $7^{\text {th }}$ edn). Churchill Livingstone, Edinburgh, Uk, pp. 521-629.

19. Faulkner WR, King JW (1970) Manual of clinical laboratory procedures. Chemical Rubber, USA, pp. 354.

20. Oyewale JO (1992) Effects of temperature and pH on the osmotic fragility of erythrocytes of domestic fowl (Gallus domesticus) and guinea fowl (Numida maleagris). Res Vet Sci 52: 1-4.

21. Jimoh A, Tanko Y, Ahmed A, Mohammed A, Ayo JO (2015) Protective effect of resveratrol co-administration with cholesterol diet on erythrocyte osmotic fragility and malondialdehyde concentration in rabbits. British Journal of Pharmaceutical Research 6(1): 14-21.

22. Aliyu M, Saleh MI A, Alhassan AW, Zuberu J, Adamu BY, et al. (2017) Evaluation of the effect of co-administration of Resveratrol and Vitamin E on Carbamazepine induced Oxidative stress in male adult Wistar rats. Journal of African Association of Physiological Sciences 5(2): 93-100.

23. Thakur S, Maheswari E, Saraswathy GR (2011) Influence of Vitamin C on phenytoin-induced haematotoxicity and oxidative stress in rats. International Journal of Pharmaceutical Research and Innovation 2: 3239.

24. Sajish M, Schimmel PA (2015) Human tRNA synthetase is a potent PARP1-activating effector target for resveratrol. Nature 519(7543): 370373.

25. Nurgül A, Ebru Y, Bayram G, Ruhi K, Fatih SB (2014) Effect of resveratrol on hematological and biochemical alterations in rats exposed to fluoride. Journal of Biomedicine and Biotechnology 2(3): 698628.

26. Alhassan A, Ayo JO, Sulaiman AF, Muftau S, Yahaya AA, et al. (2010) Effects of co-administration of antioxidants on erythrocyte osmotic fragility of Wistar rats during the hot-dry season. European Journal of Scientific Research 46(1): 75-79.

27. Pandey KB, Rizvi SI (2010) Biomarkers of oxidative stress in red blood cells. Biomed Pap Med Fac Univ Palacky Olomouc Czech Repub 155(2): 131-136.

28. Matough FA, Budin SB, Hamid ZA, Louis SR, Alwahaibi N, et al. (2012) Palm vitamin E reduces oxidative stress, and physical and morphological alterations of erythrocyte membranes in streptozotocin-induced diabetic rats. Oxidants and Antioxidants in Medical Science 1(1): 59-68. 


\section{ISSN: 2574-1241}

DOI: 10.26717/BJSTR.2019.16.002813

Munira Aliyu. Biomed J Sci \& Tech Res

(c) (i) This work is licensed under Creative

Submission Link: https://biomedres.us/submit-manuscript.php

$\begin{array}{ll}\text { BIOMEDICAL } & \text { Assets of Publishing with us } \\ \text { RESEARCHES } & \text { - Global archiving of articles } \\ \text { - Immediate, unrestricted online access } \\ \text { - Rigorous Peer Review Process }\end{array}$

